\title{
IL-4 POLYMORPHISM IN PATIENTS WITH ACUTE BRUCELLOSIS IN THE REPUBLIC OF AZERBAIJAN
}

\author{
Elchin Mammad oglu Huseynov \\ Department of Infectious Diseases \\ Azerbaijan Medical University \\ 23 Bakikhanov str., Baku, Azerbaijan, AZ1022 \\ elchinhuseynov@mail.ru
}

\begin{abstract}
Currently, there are isolated data on the relationship between IL-4 polymorphism (C-589T) and susceptibility to brucellosis. Therefore, the purpose of the study was to determine the frequency of polymorphism of IL-4 (C-589T) in patients with acute brucellosis.

Materials and methods: the article presents the results of surveys of 120 patients with acute brucellosis. The control group consisted of 30 practically healthy persons. The diagnosis of brucellosis was based on complaints, anamnesis, epidemiological and clinical data, and the results of a specific study. The definition of the polymorphism of IL-4 (C-589T) was performed for all patients in the main and control group. A detailed description of patients with brucellosis is presented. Among the observed prevailed men and young people of working age.

Results: A mild degree was established in 74 (61.66 \%) patients, while severe - only in $11(9.17 \%)$ patients. It was determined that the genotype CT (65.83\%) was significantly more common among patients with brucellosis than in the control group, where the frequency of this genotype was only $16.66 \%$. While the CC genotype was 3.2 times more common among healthy individuals than among patients in the main group (76.67\% versus $24.17 \%$ ), it was found that the CC genotype of the IL-4 gene was 13 times more common in patients for acute brucellosis with mild progress than with severe.
\end{abstract}

Conclusions: The genotype IL-4 (C-589T) SS is significantly associated with the mild course of brucellosis.

Keywords: acute brucellosis, cytokine, interleukin-4, polymorphism, genotype.

\section{Introduction}

Brucellosis is one of the most common zoonotic infections in the world with a high percentage of chronic forms. This is respectively negatively affects the economic component of health systems in countries with high prevalence of brucellosis [1, 2]. One of the highest rates of brucellosis morbidity is observed in Central Asia and Eastern Europe [3, 4]. A high level of morbidity remains in Azerbaijan, especially in areas where livestock is actively involved. According to various data in the world from a few million to 500 thousand new cases of brucellosis is recorded annually $[5,6]$.

In the pathogenesis of acute brucellosis, the immunological imbalance is emerging. $\mathrm{Cy}$ tokines play one of the key roles in modulating the immune response. One of the factors that influence the activity of cytokines is polymorphisms, which encode protein molecules of genes of cytokines $[7,8]$.

Serum IL-4 levels are generally elevated in patients with acute brucellosis, since it is an anti-inflammatory cytokine that activates humoral immunity and also participates in the control of the proliferation and differentiation of B cells and T-helper cells. The role of the IL-4 polymorphism for some diseases, including Behcet's disease [9], has been proved. Also, for the diseases of the pathogenesis, an important role is played by the immunoallergic component, namely, at atopic bronchial asthma, rheumatoid arthritis, chronic obstructive pulmonary disease, allergic rhinitis $[10,11]$. The above data indicates the universality of the IL-4 gene, which is capable of participating in the inflammatory reaction of any genes, including in brucellosis.

At present there are small, conflicting data on the relationship between IL-4 polymorphism and brucellosis susceptibility. Yes, by Ozgur Gunal et al. in 2017, it was found that individuals with P1 and P2P1 polymorphisms of the genotype IL-4 VNTR are susceptible to brucellosis [12]. Then, as investigated by Manoochehr Rasouli et al., 2007, IL-4CC polymorphism was found to be related to brucellosis resistance [13]. 


\section{Aim of the research}

Determine the frequency of polymorphism of IL-4 (C-589T) in patients with acute brucellosis in the Republic of Azerbaijan.

\section{Materials and methods of the research}

In the framework of this work 178 patients with signs of brucellosis were examined, who applied for medical assistance at Baku Clinic and the Central Clinical Hospital of Baku during 2012-2017. All patients gave a permission to include them in the study.

The diagnosis of acute brucellosis was established on the basis of clinical data, anamnesis, including epidemiological, data of objective examination, results of specific and nonspecific laboratory diagnostics.

Specific methods of the study were conducted using ELISA on Awareness and StatFax 3200 devices using NovaLisa BrusellaI gG, IgM (Germany) test systems for detecting IgM and IgG.

Criteria for inclusion in the study were to establish the diagnosis of acute brucellosis, while taking into account the duration of clinical symptoms, namely, 3 months from the date of the first complaints, as well as the presence of specific markers of acute brucellosis.

According to the criteria for inclusion in a study of 178 patients surveyed, only 120 persons, who were the main group, fully met all criteria. The control group consisted of 30 practically healthy persons who underwent a planned annual review. The groups were representative by age and gender. Patients of both groups are ethnic Azerbaijani who live permanently in Azerbaijan. The average age of patients in the main group was $35.9 \pm 2.8$ years. Among the surveyed, male subjects were dominated by $75.00 \%$.

Criteria for exclusion from the study: persons under the age of 18 years, confirmation of the diagnosis of subacute or chronic brucellosis, the presence of severe chronic concomitant pathology, which could significantly affect the reliability of the results.

Also, the definition of the polymorphism of IL-4 (C-589T) was performed for all patients in both groups. The amplification of the DNA of the studied loci was carried out automatically using the following primers: 5'AACACCTAAACTTGGGAGGA3 and 5'CTGTCATGGAAAAGCTGATCT3'. After initial denaturation at $94^{\circ} \mathrm{C}$ for 5 minutes each stage took place in 3 stages: denaturation $94{ }^{\circ} \mathrm{C}(30 \mathrm{~s})$, annealing of primers $(30-45 \mathrm{~s})$, elongation $-72^{\circ} \mathrm{C}(30-40 \mathrm{~s})$. The final elongation lasted 7 minutes at $72^{\circ} \mathrm{C}$. The allelic isolation of IL- 4 gene was used to limit the restriction of the amplicons using the AvaII endonuclease restriction. The products of the hydrolysis of the amplified sequences were analyzed by electrophoresis in a $2 \%$ agarose gel.

The reliability of the differences in the distribution of genotypes by polymorphic loci between the groups was verified to correspond to the Hardy-Weinberg equilibrium.

The statistical processing of the obtained results was carried out using the program "STATISTICA 6.0". Student's parametric test was used to compare two independent samples and one-dimensional dispersion analysis to compare more than 2 independent samples. Values of $\mathrm{p}<0.05$ were considered as reliable.

\section{Results of the research}

In the analysis of polymorphism of the IL-4 (C-589T), it was found that the genotype CT $(65.83 \%)$ is significantly more common among patients with brucellosis than in the control group, where the frequency of this genotype was only $16.66 \%$. Whereas, the CC genotype was 3.2 times more common among healthy individuals than among patients in the main group (76.67 \% vs. $24.17 \%$ ). Regarding the distribution frequency of the alleles C and T, IL-4 (C-589T), a significant difference was found only among healthy subjects, so the frequency of carriers of allele $\mathrm{C}$ was 5.7 times higher than the allele $\mathrm{T}$ frequency $(\mathrm{p}<0.05)$ (Table 1).

Taking into account the above results and the data available that the level of IL-4 can significantly change depending on the severity of brucellosis [14, 15], we have decided to analyze the frequency of detection of the polymorphism of IL-4 (C-589T) depending on the degree of severity. To do this, all 120 patients with acute brucellosis were divided into three subgroups of severity. The following symptoms were the criterion of severity: fever, sweating, chills, headache, insomnia, low 
blood pressure, tachycardia, hepatosplenomegaly, myocarditis, pericarditis, endocarditis, changes in the general blood count, levels of pro-inflammatory and anti-inflammatory cytokines [16]. Thus, an easy degree was established in 74 (61.66 \%) persons, the moderate degree was $35(29.17 \%)$ and in only $11(9.17 \%)$ patients the condition was severe (Fig. 1).

Table 1

Frequency of detection of polymorphism (C-589T) of the gene IL-4 in patients with acute brucellosis and healthy individuals

\begin{tabular}{ccccc}
\hline & \multicolumn{2}{c}{ Patients with brucellosis } \\
Genotypes and alleles IL-4(C-589) & \multicolumn{2}{c}{$\begin{array}{c}\text { Healthy individuals } \\
(\mathbf{n = 3 0})\end{array}$} \\
\cline { 2 - 5 } & Abs. & $\mathbf{\%}$ & Abs. & \% \\
\hline CC & 29 & 24.17 & 23 & $76.67^{*}$ \\
CT & 79 & 65.83 & 5 & $16.66^{*}$ \\
TT & 12 & 10.00 & 2 & 6.67 \\
Allele C & 137 & 57.08 & 51 & 85.00 \\
Allele T & 103 & 42.92 & 9 & 15.00
\end{tabular}

Note: $*_{-}-p<0.05$ - between patients with acute brucellosis and healthy persons

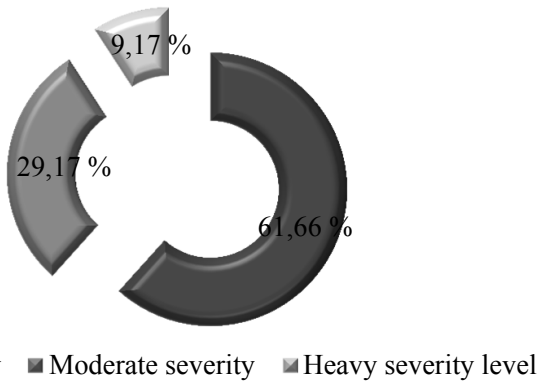

Fig. 1. Distribution of patients with brucellosis depending on severity

It was found that the CC genotype of the IL-4 gene was 13 times more likely to be detected in patients with acute brucellosis than in severe cases $(p<0,05)$. In other genotypes, no reliable differences were found (Table 2).

Table 2

Frequency of detection of polymorphism (C-589T) of IL-4 gene in patients with brucellosis

\begin{tabular}{|c|c|c|c|c|c|c|}
\hline \multirow{3}{*}{$\begin{array}{c}\text { Genotypes } \\
\text { IL-4(C-589T) }\end{array}$} & \multicolumn{6}{|c|}{ Patients with brucellosis $(\mathrm{n}=120)$} \\
\hline & \multicolumn{2}{|c|}{ Easy severity $(n=74)$} & \multicolumn{2}{|c|}{ Moderate severity $(n=35)$} & \multicolumn{2}{|c|}{ Heave severity level $(n=11)$} \\
\hline & Abs. & $\%$ & Abs. & $\%$ & Abs. & $\%$ \\
\hline $\mathrm{CC}$ & 28 & 37.84 & 1 & $2.86^{*}$ & 0 & 0 \\
\hline $\mathrm{CT}$ & 39 & 52.70 & 31 & 88.57 & 9 & 81.82 \\
\hline TT & 7 & 9.46 & 3 & 8.57 & 2 & 18.18 \\
\hline
\end{tabular}

Note: ${ }^{*}-p<0.05$ - between patients with brucellosis with different degrees of severity.

\section{Discussion of the results}

The role of IL-4 polymorphism and its relationship with brucellosis is ambiguous and poorly understood. Currently, there are isolated data, so in one study, the polymorphism of the IFN- $\gamma$ and IL-4 genes at positions +874 and -590 , respectively, in patients with brucellosis was analyzed. Based on their analysis, the researchers concluded that individuals with an IFN- $\gamma$ AA genotype are more susceptible, and those with an IL-4CC genotype are more resistant to brucellosis. That 
is, Rasouli M. et al. 2007, it is believed that carriers of the genotype CC IL-4 are more resistant to brucella infection, indicating the protective effect of this genotype [13].

A group of Turkish researchers analyzed another polymorphism of the IL-4, namely, VNTR, concluding that carriers of the P1 allele and the P2P1 IL-4VNTR genotype are at risk for the development of brucellosis [12].

Rezazadeh M. et al., in 2006 found that the genotype CT of the gene IL-4 (C-589T) is associated with a significantly greater risk of developing brucellosis with a correlation of chances of 4.2 (95\% CI 2.7-6.6, p<0.0001) [17].

The data obtained by us in some ways coincide with previous studies, so that the genotype of CC IL-4 (C-589T) was 3.2 times more commonly registered among healthy individuals than among patients with brucellosis, and more often associated with the mild course of the disease [18].

Taking into account the analyzed literature data and the data we have received, we consider, like most researchers that the ambiguity of the results may be due to the diversity of ethnic groups that participated in various studies $[19,20]$.

\section{Conclusions}

1. The genotype of CC IL-4 (C-589T) was 3.2 times more common among healthy individuals than among patients with brucellosis, whereas the CT genotype, on the contrary, was 3.9 times more frequently recorded among patients.

2. It was established that the genotype IL-4 (C-589T) CC is significantly associated with the mild progression of brucellosis.

\section{Referenes}

[1] Najafi, N., Davoudi, A., Hassantabar, S. R., Haddadi, R. (2018). Investigating the Epidemiologic, Laboratory, and Clinical Features of Brucellosis Patients Hospitalized in the North of Iran During 2009-2014. Archives of Clinical Infectious Diseases, 13 (2). doi: http://doi.org/10.5812/archcid.61012

[2] Mugahi, S., Nashibi, R., Alavi, S. M., Gharkholu, S., Najafi, K. (2014). Epidemiological Features, Clinical Manifestation and Laboratory Findings of Patients With Brucellosis. Archives of Clinical Infectious Diseases, 9 (1). doi: http://doi.org/10.5812/archcid.17270

[3] Pappas, G., Akritidis, N., Bosilkovski, M., Tsianos, E. (2005). Medical progress: brucellosis. New England Journal of Medicine, 352 (22), 2325-2336. doi: http://doi.org/10.1056/nejmra050570

[4] Garcell, H. G., Garcia, E. G., Pueyo, P. V., Martín, I. R., Arias, A. V., Alfonso Serrano, R. N. (2016). Outbreaks of brucellosis related to the consumption of unpasteurized camel milk. Journal of Infection and Public Health, 9 (4), 523-527. doi: http://doi.org/10.1016/j.jiph.2015.12.006

[5] Nourbakhsh, F., Borooni, S., Barangi, S., Tajbakhsh, E. (2017). Diagnosis of clinical and laboratory findings of brucellosis in Isfahan. International Archives of Health Sciences, 4 (2), 48. doi: http:// doi.org/10.4103/iahs.iahs_1_17

[6] Ahmad Reza, M., Samira, A., Amir Hossein, H., Behnam, S. et. al. (2017). Serum interferon-gamma and interleukin-4 in patients with brucellosis before and after treatment. Asian Pacific Journal of Tropical Disease, 7 (7), 396-400. doi: http://doi.org/10.12980/apjtd.7.2017d6-464

[7] De Figueiredo, P., Ficht, T. A., Rice-Ficht, A., Rossetti, C. A., Adams, L. G. (2015). Pathogenesis and Immunobiology of Brucellosis. The American Journal of Pathology, 185 (6), 1505-1517. doi: http://doi.org/ 10.1016/j.ajpath.2015.03.003

[8] Rodriguez-Zapata, M., Matias, M. J., Prieto, A., Jonde, M. A., Monserrat, J., Sanchez, L. et. al. (2010). Human Brucellosis Is Characterized by an Intense Th1 Profile Associated with a Defective Monocyte Function. Infection and Immunity, 78 (7), 3272-3279. doi: http://doi.org/10.1128/iai.01385-09

[9] Inanir, A., Tural, S., Yigit, S., Kalkan, G., Pancar, G. S., Demir, H. D., Ates, O. (2013). Association of IL-4 gene VNTR variant with deep venous thrombosis in Behçet's disease and its effect on ocular involvement. Molecular vision, 19, 675-683.

[10] Micheal, S., Minhas, K., Ishaque, M., Ahmed, F., Ahmed, A. (2013). IL-4 Gene Polymorphisms and Their Association With Atopic Asthma and Allergic Rhinitis in Pakistani Patients. Journal of Investigational Allergology and Clinical Immunology, 23 (2), 107-111. 
[11] Trajkov, D., Mirkovska-Stojkovikj, J., Petlichkovski, A., Strezova, A., Efinska-Mladenovska, O., Sandevska, E. et. al. (2009). Association of cytokine gene polymorphisms with chronic obstructive pulmonary disease in Macedonians. Iranian Journal of Allergy, Asthma and Immunology, 8 (1), 31-42.

[12] Gunal, O., Yigit, S., Yalcın, A. D., Celik, B., Barut, S., Demir, O. et. al. (2017). The IL4-VNTR P1 Allele, IL4-VNTR P2P2 Genotype, and IL4-VNTR_IL6-174CG P2P1-GG Genotype Are Associated with an Increased Risk of Brucellosis. Japanese Journal of Infectious Diseases, 70 (1), 61-64. doi: http://doi. org/10.7883/yoken.jjid.2015.550

[13] Rasouli, M., Kiany, S. (2007). Association of interferon-gamma and interleukin-4 gene polymorphisms with susceptibility to brucellosis in Iranian patients. Cytokine, 38 (1), 49-53. doi: http://doi.org/ 10.1016/j.cyto.2007.05.003

[14] Sanaei Dashti, A., Karimi, A., Elyasi, B., Shamshiri, A. R., Shoja, S. A., Shamshiri, M. (2017). Cytokine Profiles in Acute Brucellosis, Compared with Those in Other Febrile Illnesses. Archives of Clinical Infectious Diseases, 12 (4). doi: http://doi.org/10.5812/archcid.66077

[15] Demirdag, K., Ozden, M., Kalkan, A., Godekmerdan, A., Sirri Kilic, S. (2003). Serum cytokine levels in patients with acute brucellosis and their relation to the traditional inflammatory markers. FEMS Immunology \& Medical Microbiology, 39 (2), 149-153. doi: http://doi.org/10.1016/s0928-8244(03)00207-4

[16] Belozerov, E. S. (1985). Brucellez. Leningrad: Medicina, 184.

[17] Rezazadeh, M., Hajilooi, M., Haidari, M., Rafiei, A., Ahmad Alavi, S., Keramat, F. (2006). Association of susceptibility to brucellosis and interleukin-4 promoter polymorphism. Scandinavian Journal of Infectious Diseases, 38 (11-12), 1045-1049. doi: http://doi.org/10.1080/00365540600786473

[18] Budak, F., Göral, G., Heper, Y., Yılmaz, E., Aymak, F., Baştürk, B. et. al. (2007). IL-10 and IL-6 gene polymorphisms as potential host susceptibility factors in Brucellosis. Cytokine, 38 (1), 32-36. doi: http:// doi.org/10.1016/j.cyto.2007.04.008

[19] Eskandari-Nasab, E., Moghadampour, M., Asadi-Saghandi, A., Kharazi-nejad, E., Rezaeifar, A., Pourmasoumi, H. (2013). Levels of Interleukin-(IL)-12p40 are Markedly Increased in Brucellosis Among Patients with SpecificIL-12BGenotypes. Scandinavian Journal of Immunology, 78 (1), 85-91. doi: http:// doi.org/10.1111/sji.12054

[20] Sofian, M., Ramezani, A., Mousavi, A., Banifazl, M., Cherei, S., Cherei, A., Aghakhani, A. (2016). Interlukine-17 and TGF- $\beta$ levels in patients with acute brucellosisbefore and after treatment. Turkish journal of medical sciences, 46, 1348-1352. doi: http://doi.org/10.3906/sag-1506-59 